

\title{
Terapia Familiar em Contexto de Adolescência e Drogadição
}

\author{
Flávio Lôbo Guimarães* \\ Liana Fortunato Costa** \\ Marcelo Ivo Silva de Lima***
}

\section{RESUMO}

O presente trabalho consiste na apresentação de um modelo de atendimento em terapia familiar realizado no contexto da clínica-escola de uma universidade. A apresentação é fundamentada com a explicitação dos referenciais teóricos e com um estudo de caso clínico. Três sessões estão descritas dentro de um atendimento terapêutico, contexto de drogadição, a uma família com pai, mãe e três filhos adolescentes. O instrumento para análise constitui-se de formulários de observações e gravações em vídeo das sessões. A análise é realizada segundo uma sistemática de estudo de caso clínico e enfoca quatro aspectos principais: rotulação, relação conjugal, pseudo-individuação e violência.

\section{Introdução}

A questão da droga é um assunto que abrange diversas áreas de trabalho social, sem, no entanto, significar um trabalho conjunto ideal entre essas áreas na resolução dos problemas que estão relacionados à dependência química. A dificuldade está em saber em que medida e até que ponto cada área pode contribuir para a obtenção de resultados satisfatórios.

Também o usuário de drogas é visto sob vários pontos de vista, variando o julgamento que se faz dele de acordo com a perspectiva teórica na qual ele é visto. Bucher (1992, p. 199) trata da posição ocupada pelos drogaditos em nossa sociedade como uma posição nem um pouco confortável: "entre o manicômio e o presídio".

De fato, a visão da sociedade a respeito desse fenômeno tem se resumido em duas principais vertentes. Uma é a visão da drogadição como criminalidade, um desvio, um vício, concebendo o usuário como um delinqüente e utilizando a repressão como forma de impedir o avanço do abuso de drogas. A outra vê a drogadição como uma doença, psiquiatrizando-a e buscando explicações psicofisiológicas que a justifiquem. Nesse caso, os drogaditos são indivíduos predispostos ao vício, com estruturas de personalidade que favorecem a instalação de uma dependência.

Ao contrário dessa visão, o problema das drogas deve ser encarado sob uma perspectiva mais abrangente, interdisciplinar. Qualquer profissional que queira se ocupar de toxicômanos deve se esquecer de seus conhecimentos e de suas técnicas baseadas em esquemas de pensamento causal e linear, uma vez que essa nova abordagem pluridimensional se impõe, pois a questão da droga escapa a qualquer abordagem unilateral (Calanca, 1991).

Assim, o usuário de drogas também deve ser entendido sob uma abordagem pluridimensional e como um ser inserido em muitos contextos, não só o médico ou o jurídico, mas também o escolar, o de trabalho, o familiar e o comunitário.

\footnotetext{
* Instituto de Medicina e Psicologia Integradas - Brasília (DF). E-mail: flaviopsi@ yahoo.com.br

** Universidade Católica de Brasília e Universidade de Brasília. E-mail: lianaf@zaz.com.br

*** Adolescentro - FHDF. E-mail: marrcelo@ hotmail.com
} 
O presente trabalho entende toda essa complexidade que envolve a questão do abuso de drogas e se propõe a contribuir dentro de uma microdimensão, a do sistema familiar. Apesar de parecer uma contribuição restrita, o estudo, reflete toda a realidade está a ele relacionada ao problema na medida em que, também na família, um membro usuário de drogas muitas vezes é visto como um bode expiatório, por não se considerar a família como participante no fenômeno.

Sternschuss e Angel (1991) ampliam a visão que se tem a respeito do adolescente usuário de droga, muitas vezes centrada apenas no indivíduo. Os autores relacionam a toxicomania com diversos fatores familiares. Primeiramente, observa-se, na maioria dos casos, a existência de patologias familiares: histórias psiquiátricas dos pais de toxicômanos, tais como depressão, alcoolismo, tentativa de suicídios, drogas etc. Segundo os autores, pode-se constatar também a existência de "transações familiares toxicomaníacas". A existência de uma estreita relação entre os pais e o jovem usuário contribui para que este permaneça, durante um bom tempo, sob essa condição.

A transgressão de uma lei na vida do jovem em situação de uso de drogas também é entendida por Sternschuss \& Angel (1991) como algo que nos permite afirmar ser essa transgressão de natureza transgeracional. $\mathrm{O}$ fato da constante transgressão das leis talvez se deva à não-interiorização de uma lei paterna ou à frequiente desvalorização das leis no contexto relacional desse jovem.

Sudbrack (1992) procura estudar a delinqüência numa perspectiva que abrange o cenário relacional, destacando a função paterna como uma dimensão fundamental na compreensão desse fenômeno. A autora menciona estudos que confirmam características comuns a famílias com "transações delitogênicas". Sudbrack utiliza o termo cunhado por Segond (1986), "designação familiar precoce", para se referir ao conjunto de comportamentos e atitudes dos pais que resultam no reconhecimento do filho como diferente, o que incorre num tratamento diferenciado em relação a ele. Muitas vezes, esse tratamento acaba por incrementar a diferença num "espiral invisível de uma designação repetitiva e patológica” (Sudbrack, 1992, p. 449).

Selekman (1996) relata sua experiência com adolescentes rotulados como "difíceis". O autor argumenta que esse tipo de rotulação só traz prejuízo ao tratamento. Calcada em uma "linguagem do déficit" (Goolishian, citado por Selekman, 1996, p. 31), a rotulação só reconhece aquilo que falta, aquilo que é ruim no adolescente. Além de reconhecer o papel da família nesse processo, Selekman chama a atenção para o envolvimento dos profissionais que, dependendo de sua perspectiva, podem incluir o adolescente dentro de uma categoria patológica, da qual será difícil se desvencilhar a partir de então.

Entre os autores que enfocam o sistema familiar como um importante cenário para a compreensão e intervenção no que tange ao uso indevido de drogas, Stanton e Todd (1988) apresentam uma modelo terapêutico e conceitual (Stanton et al., 1988) que se revela bastante útil para o tratamento de famílias de adolescentes. Tal modelo constitui um dos principais eixos norteadores do trabalho dos presentes autores e será aqui tratado com maior atenção.

No modelo conceitual (Stanton et al., 1988) os autores argumentam que o abuso de drogas tem, muitas vezes, origem na adolescência e está relacionado com o processo normal de crescimento, auto-afirmação, experimentação de coisas novas, desenvolvimento de relações íntimas com pessoas de fora da família e com a saída do lar. Os autores reconhecem três etapas distintas no que se refere ao abuso de drogas. A primeira refere-se ao uso de drogas legais, principalmente o álcool, e pode ser compreendida como um fenômeno social. A segunda implica o uso de maconha e é marcada pela grande influência dos grupos de pares. Já a terceira etapa envolve o uso de 
outras drogas ilegais e é a fase que está intimamente ligada a questões familiares, principalmente às relações entre pais e adolescentes.

A análise de casos clínicos de famílias de usuários de drogas permitiu que os autores percebessem padrões de comportamentos comuns à boa parte delas. No que se refere às relações do jovem em situação de uso de drogas com a família, percebe-se uma manutenção de estreitos laços. O indivíduo encontra-se intimamente envolvido com as questões familiares, apesar de um aparente distanciamento e independência propiciados pelo universo que envolve o uso de drogas.

Lemos, citado por Stanton et al. (1988), afirma que os estudos de famílias de drogaditos do sexo masculino revelam em muitos casos uma relação muito próxima entre mãe e filho, podendo-se dizer até simbiótica, enquanto a relação pai-fillho mantém-se marcada por um maior distanciamento. Em muitos casos se observa uma relação conflituosa, descrita como bastante negativa por parte do filho. É interessante ressaltar, porém, que em uma pequena porcentagem de casos se observou uma relação simbiótica entre a díade pai-filho.

Assim, de acordo com os autores, a drogadição pode ser considerada como parte de um processo cíclico, que envolve três ou mais indivíduos, normalmente o adolescente em situação de uso de drogas e seus pais. Essa relação triangular tem a função de reduzir a ansiedade do sistema quando esta alcança níveis muito elevados. Isso ocorre, por exemplo, quando o casal entra em conflito, o que traz a ameaça de uma separação. Nesse momento, o jovem usuário se ativa, age de forma a concentrar a atenção sobre ele, por meio do abuso de drogas, da delinquiência, da agressividade. $O$ comportamento do jovem tem, assim, efeito imediato sobre o casal, que esquece temporariamente suas diferenças conjugais e passa ao papel de pais excessivamente apegados.

Pode-se observar, portanto, que o comportamento do adito cumpre um papel muito importante na dinâmica familiar: a função de conservar o equilíbrio da união do sistema familiar (Stanton et al., 1988). Esse importante papel coloca o jovem em uma posição muito difícil. De um lado, há uma pressão da sociedade para que ele cresça e se torne um indivíduo responsável; de outro, há uma pressão familiar para que ele nunca saia de dentro do núcleo familiar e seja sempre o filhinho que necessita constantemente da atenção e preocupação dos pais.

A droga apresenta-se, portanto, como uma solução paradoxal para esse dilema do jovem usuário e de sua família. Com ela, ele alcança a sua independência, deixa a família, relaciona-se com seu grupo de pares. Trata-se, porém, de uma pseudoindependência, pois esse comportamento do jovem faz com que seus pais voltem seus olhos para ele e se envolvam profundamente com sua vida pessoal. É o que Stanton e Todd (1988) denominam pseudo-individuação.

A observação desses padrões de comportamento em famílias de drogaditos propiciou a formulação de um modelo de intervenção. Esse modelo terapêutico se baseia fundamentalmente na terapia familiar estrutural e na terapia familiar estratégica. Estas duas escolas possuem visões semelhantes da família, do papel do terapeuta e do processo: visão dos indivíduos em seus contextos; importância do ciclo de vida na compreensão da dinâmica familiar; visão de causalidade circular; ênfase no presente; tratamento feito de forma pragmática, com o objetivo de mudanças de seqüências comportamentais; maior ênfase no processo, em detrimento do conteúdo; diretividade; uso de redefinições; uso de tarefas para consolidar as mudanças; utilização de alianças com membros das famílias (Stanton e Todd, 1988).

Trata-se de um enfoque estrutural-estratégico ao abuso de drogas. Esse enfoque consiste em, como dizem os próprios autores, aplicar a teoria estrutural de Salvador 
Minuchin (1982) como paradigma orientador, trabalhar estruturalmente dentro das sessões e aplicar o modelo estratégico de Jay Haley (1985), quando se dá ênfase a uma meta específica ou a acontecimentos fora das sessões (Stanton e Todd, 1988).

Esse modelo caracteriza-se por ser de curto prazo, por desencadear mudanças mais rápidas. $\mathrm{O}$ tratamento deve se iniciar enfocando a tríade composta pelo jovem em situação de uso drogas e seus progenitores. De acordo com os autores, esse é um passo fundamental para o sucesso da terapia. À medida que os pais vão liberando o adolescente dessa relação triangular, a terapia vai mudando o seu foco. Apesar do enfoque na tríade, a participação de toda a família de origem é incentivada. O papel dos irmãos é muito importante. Eles podem fazer alianças fortalecendo um membro da família ou apoiando a postura de outro. Além disso, a presença dos irmãos dilui a atenção, que às vezes pode estar por demais concentrada no jovem usuário. Um outro motivo é o fato de os terapeutas terem uma idéia mais real dos padrões interacionais da família com a presença de todos os membros. Outros sistemas podem ser eventualmente utilizados. A seguir, serão apresentados os componentes fundamentais do modelo terapêutico, de Stanton e Todd (1988).

\section{Atribuições nobres}

Uma das características principais das famílias de drogaditos consiste na sua grande defensividade. Por isso, o processo terapêutico requer muito bom senso dos terapeutas. Observou-se que as técnicas de confrontação não funcionam bem com as famílias, ao contrário, resultam em maior resistência. Assim, um caminho utilizado pelos terapeutas estratégicos consiste em conotações positivas e redefinições. A adoção de uma posição não acusatória reduz a resistência dos pais e resgata sua competência, já que esta será absolutamente necessária para o sucesso do tratamento.

Essa concepção utiliza-se de manejos que consistem numa forma de se aliar com os membros da família, redefinindo sua conduta dentro de um contexto mais amplo, o sistêmico. Um comportamento tido como inaceitável quando visto de forma isolada pode ser compreendido de maneira diferente quando se percebe sua função dentro do contexto familiar. Nesse sentido, o uso de drogas e a delinqüência podem ser, por exemplo, interpretados como formas de manter unido um casal ou toda uma família.

São comuns os usos de metáforas nessas redefinições. Elas constituem um modo de falar daquilo que se quer, sem tocar no assunto. Algumas vezes o uso de intervenções paradoxais se mostra também muito útil para as atribuições nobres.

\section{Metas do atendimento familiar}

Outro recurso utilizado pelo modelo terapêutico de Stanton e Todd (1988) é o estabelecimento de metas desde o início da terapia. De uma forma geral, as metas fundamentais que norteiam o trabalho terapêutico são: fim do uso de drogas por parte do adolescente; utilização do tempo de uma forma produtiva (trabalho, estudos); estabelecimento de autonomia, culminando com a saída de casa. Recomenda-se aos terapeutas que focalizem o uso de drogas nas sessões até que observem uma melhoria estável. A partir daí é possível abordar outras metas do tratamento.

\section{Concentração na conduta concreta}

Outra característica desse enfoque, que consiste em uma herança das terapias estruturais e estratégicas, é a concentração nos comportamentos observáveis. Esse modo de conceber a terapia está de acordo com as bases epistemológicas que se concentram muito mais nos sintomas, nos processos, do que propriamente em suas causas ou significações. Assim, os terapeutas se mantêm atentos às sequiências comportamentais 
que ocorrem nas sessões. Por meio delas, eles obtêm uma noção mais real daquilo que ocorre no dia-a-dia da família, podendo até intervir nessas seqüências introduzindo algum elemento que as possa modificar, ou utilizando-se de redefinições para compreender a função destas num contexto mais amplo.

\section{Reestruturação}

Para as mudanças necessárias ao sucesso do tratamento, o terapeuta tem de intervir estruturalmente. Uma intervenção essencial consiste em conseguir que os pais colaborem com a recuperação do adolescente, rompendo o padrão homeostático. Para isso, o adito terá de, por exemplo, sair de sua posição triangulada no relacionamento do casal ou terá de se aproximar do pai ou de afastar-se de uma relação simbiótica que mantém com a mãe, saindo do papel, muitas vezes assumido, de pseudocônjuge. Essas reestruturações não raro têm seu início no próprio setting terapêutico. É nesse contexto que os terapeutas tentam modificar padrões relacionais estabelecidos. Para isso é necessário que, em algumas ocasiões, o clima de ansiedade que se impõe na sessão não seja ignorado ou minorado.

\section{Questão conjugal}

Uma das questões mais delicadas no processo terapêutico é a relação conjugal. Vê-se que o abuso de drogas por parte de um membro da família está relacionado a conflitos familiares e conjugais. O propósito é que esses conteúdos emerjam durante a terapia. Entretanto, o terapeuta deve ter consciência de que há momentos mais adequados no processo terapêutico para que essa questão possa ser tratada. Como se viu, o objetivo central da terapia deve ser o de que o drogadito deixe o uso de drogas. Para isso, é necessário que os pais estejam trabalhando juntos e que se mantenham em seus papéis de pais, não de cônjuges.

É importante lembrar que a demanda da família refere-se à dependência de drogas e não ao relacionamento conjugal. Um terapeuta que não leva isso em consideração corre o risco de perder os clientes logo nas primeiras sessões. A questão conjugal pode ser abordada depois que se alcançar certa estabilidade. Nesse momento, é importante que os terapeutas estejam sempre atentos ao adolescente dando-lhe o apoio necessário para que ele consiga manter-se fora do subsistema conjugal, apesar da ansiedade que isso possa causar a todos os membros da família. Dessa forma, o terapeuta estará intervindo estruturalmente e contribuindo para uma nova forma de funcionamento familiar.

\section{"O filho pródigo"}

\section{Contexto de atendimento clínico}

O trabalho realizado com essa família segue alguns aspectos da linha de trabalho desenvolvida pelo grupo de Milão. São realizadas sessões com intervalos de três semanas, pois segundo o próprio grupo (Selvini Palazzoli et al., 1988), percebe-se que num intervalo curto - uma semana, por exemplo - não é respeitado o período de tempo necessário para que o sistema familiar mostre evidências de mudanças.

A família é atendida por uma equipe composta de cinco estagiários de psicologia, um aluno de mestrado e uma professora-supervisora, sendo que uma dupla terapêutica fica na sala com a família e o restante da equipe atrás do espelho unidirecional. A comunicação entre os dois ambientes, quando necessária, é feita por meio de um interfone. A dupla é formada pela professora-supervisora e um estagiário, que conduzem a sessão, seguindo, na medida do possível, as hipóteses formuladas pela equipe antes do atendimento e conforme os conteúdos trazidos pela família. 
O atendimento leva cerca de duas horas e trinta minutos. No decorrer das sessões, se necessário, são realizados intervalos para que os terapeutas se reúnam com o restante da equipe e delineiem melhor o caminho da sessão. Há ainda um último intervalo para que a equipe terapêutica apresente à família uma resposta, uma impressão ou até mesmo uma tarefa relacionada aos conteúdos emergentes no dia. Este é o momento-chave da sessão denominado devolução, que é uma tentativa de integração de um modelo que complemente pontos da Escola de Milão e referenciais construtivistas (Boscolo et al., 1993).

Seguindo ainda a orientação desses autores, a equipe trabalha com tarefas e enfoca principalmente a conotação positiva. As tarefas são o que a equipe de Milão chama de "rituais", que é um ordenamento de comportamentos que a família deve seguir ou executar nos intervalos de uma sessão para outra.

O uso da conotação positiva se mostra importante nesse trabalho pelo que já foi exposto na prática do trabalho de Stanton e Todd (1988) no tópico "atribuições nobres". Vale lembrar aqui, que conotação positiva "é a mensagem através da qual o terapeuta indica à família que o problema é, no seu contexto, lógico e significativo" (Boscolo et al., 1993, p.18).

O trabalho inclui ainda a utilização de recursos psicodramáticos, a formação de imagens, ou seja, os terapeutas, juntamente com a família, montam imagens com os recursos humanos e materiais de que dispõem no momento para que todos possam visualizar melhor determinadas situações (Costa e Sudbrack, 1996). O objetivo é fornecer uma outra via de expressão, a corporal, para a conversação. Ainda segundo Boscolo et al. (1993), a equipe busca a construção de metáforas advindas de conteúdos da própria família, ou também a criação de metáforas elaboradas pela própria equipe.

\section{A família}

A família nuclear é composta por cinco membros: o casal e seus três filhos. O pai, Paulo ${ }^{1}$ (51 anos), é um engenheiro civil e trabalha para uma empresa estatal; a mãe, Sandra (48 anos), é uma dona de casa. A filha mais velha, Carla (22 anos), cursa o terceiro grau; o segundo filho, Ricardo (20 anos), concluiu o segundo grau e, no momento, ainda não retornou aos estudos; a filha caçula, Fernanda (18 anos), está cursando o segundo grau. Todos residem na mesma casa em um bairro de classe média alta.

A família já passou por uma experiência anterior de terapia familiar por um curto espaço de tempo, o que, na opinião do pai, foi muito bom porque serviu para mostrar que todos têm problemas. Por meio desta terapeuta, a família foi encaminhada, então, para um atendimento em contexto clínico específico a drogadição.

A principal queixa é o mau comportamento de Ricardo e seu envolvimento com drogas (maconha). A primeira sessão coincide com a data em que Ricardo está retornando de uma temporada de três meses em uma cidade do interior, local onde vive parte da família do pai. Ricardo fora morar naquele local para a fim de receber ajuda para se afastar das drogas, com a promessa de viver com a avó e trabalhar com o tio. Porém ele retornou pelo fato de não ser mais aceito na casa de sua avó e por ter roubado uma soma em dinheiro do tio.

\section{O material analisado}

O material clínico analisado refere-se a quatro de oito sessões de terapia de família. Essas sessões foram registradas por observadores (estagiários posicionados atrás do espelho unidirecional) e gravadas em vídeo, e delas foram retirados os registros das falas. O conteúdo apresentado aqui consiste em sínteses de momentos considerados 
ilustrativos do modelo de atendimento dos presentes autores. O material apresentado não se encontra em forma literal por uma questão de espaço e para facilitar a compreensão do leitor. Além disso, foi selecionado, de acordo com quatro pontos fundamentais que serão privilegiados na análise: a rotulação, a pseudo-individuação, a questão conjugal e a violência.

\section{Primeira sessão}

Participantes: Paulo, Sandra, Carla, Ricardo e Fernanda.

A primeira parte da sessão inicia-se com a apresentação dos terapeutas e da forma de trabalho da equipe. Em seguida, dedica-se grande parte da sessão à apresentação da família: cada um fala um pouco de si, do que faz etc. Logo de início, os terapeutas utilizam questionamentos circulares (Boscolo et al., 1993) para mapear as relações dentro do sistema familiar. Perguntas como "Quem ficou feliz com a volta do Ricardo?" procuram explorar as alianças, os vínculos afetivos. São percebidas posições críticas por parte do pai e da filha mais velha (Carla) em relação a Ricardo e um vínculo importante entre mãe e filho. Perguntas acerca da rotina da casa também são feitas: quem almoça com quem, quem sai com quem etc. Essas questões também se revelam bastante úteis, e um mapa estrutural (Minuchin,1982) começa a se delinear.

Após a apresentação de cada membro e da família de uma forma geral, os terapeutas perguntam de que forma a equipe pode ajudá-los. Nesse momento, as respostas começam a concentrar-se sobre Ricardo. Dizem que ele é uma pessoa capaz, mas não aproveita suas capacidades.

Utilizando-se de conotações positivas, os terapeutas fornecem uma visão mais ampla: "As drogas podem estar promovendo o sonho de união da família". É a função do sintoma. Com essa redefinição, a terapeuta alia-se a Ricardo e volta à questão da união e comunicação na família. Acrescenta perguntas acerca do que se pode fazer para um futuro de união, ou de como a família pode se ajudar.

Outra redefinição ocorre quando a terapeuta explicita o motivo de todos estarem ali. Não é pelos problemas causados por Ricardo, mas pelo amor que todos sentem por ele. Nesse momento Ricardo, que tinha permanecido calado nos últimos instantes, se sente mais à vontade para falar e até criticar os outros, mostrando que eles não são perfeitos.

Em outro momento, os terapeutas propõem que a família se organize na sessão, como se estivesse em sua sala, para assistir TV. A técnica de escultura familiar (Andolfi, 1981) objetiva, entre outras coisas, colher informações sobre as fronteiras e subsistemas. Primeiramente constata-se que Ricardo é "colocado de lado" na família e que o casal não se senta no mesmo sofá. No arranjo de Carla, Ricardo fica de fora do subsistema fraternal e ao lado da namorada. A terapeuta volta a perguntar em que a equipe pode ajudar. Novamente o foco se volta para o Ricardo. Após o intervalo, a devolução é lida, e uma tarefa é dada para a família: o pai vai buscar a "parábola do filho pródigo" (Lucas, 15) e reunir a família toda. O texto será lido e todos discutirão sobre o que tem a parábola a ver com a família e como ela poderá louvar a volta do filho pródigo.

De acordo com as orientações de Stanton e Todd (1988) e com a utilização de questionamentos circulares (Boscolo et al., 1993), procurou-se conhecer a família por meio de perguntas que evidenciassem as formas de interação de seus membros. As perguntas foram feitas sobre a família e para a família. Buscou-se incentivar interações na própria reunião, utilizando-se até de recursos dramáticos. As perguntas dos 
terapeutas relacionaram-se ao tempo presente. Procurou-se explorar o cotidiano da família para se ter uma idéia dos padrões interacionais na atualidade.

Um segundo momento ocorre na sessão quando se abordam as razões de todos estarem ali. Observa-se que a família coloca Ricardo como o bode expiatório de seus problemas. Este pode ser considerado um padrão homeostático da família: no momento em que novas possibilidades são introduzidas, todos começam a repetir as críticas a Ricardo e se retiram do foco. Os terapeutas questionam a respeito da união e comunicação na família e, assim, aliam-se a Ricardo para que ele tenha mais espaço.

A prescrição de tarefa, como foi anteriormente citado, consiste em um recurso bastante utilizado pela terapia familiar estratégica e visa consolidar mudanças. No trabalho com adolescentes drogaditos, é crucial que a autoridade e a responsabilidade dos pais sejam reconhecidas e respeitadas por todos (Stanton e Landau-Stanton, 1991). Essa tarefa, especificamente, objetivou qualificar o pai como o chefe da família, pois é ele quem deve organizar para que ela seja cumprida. Além disso, a parábola "O filho pródigo" é um recurso para que eles conversem entre si e percebam o posicionamento de cada um em relação a essa nova fase em que a família se encontra (recepção a Ricardo).

\section{Terceira sessão}

Participantes: Paulo, Sandra, Carla, Ricardo, Fernanda.

As recordações trazidas no início desta sessão acerca dos anos em que os filhos eram pequenos foram estimuladas pelos terapeutas com a utilização da técnica da Linha da Vida. A partir dela, nota-se, logo de início, a importância dos filhos nessa família na medida em que quase todos os eventos citados têm relação com eles (nascimento, desenvolvimento, maioridade, problemas com drogas, formatura etc.). À medida que relata, a família se dá conta de que há muito tempo não faz um programa em conjunto.

Instala-se um clima de maior ansiedade quando a questão da droga emerge. Em 1994, os pais de Ricardo descobriram o seu envolvimento com maconha. Nota-se que Ricardo fica bastante ansioso (suas pernas tremem) e calado no momento em que estes fatos são revelados. Enquanto isso, os pais relatam as tentativas anteriores da família em solucionar este problema: Amor Exigente, ${ }^{2}$ terapia familiar, contatos com clínicas.

Surge uma história bastante significativa sobre um episódio em que Ricardo saiu de casa. A mãe revela que, na verdade, ela mesma o colocara para fora pelos problemas que vinha causando. Sandra alega que queria proteger suas filhas. Paulo, o pai, ao contrário, ajoelhou-se aos pés do filho e pediu para que ele ficasse. Mas já era tarde, Ricardo decidira partir. Ele saiu de casa e foi para uma quitinete próxima à casa de sua avó materna, onde fazia as refeições todos os dias.

A terapeuta pergunta a Ricardo como ele se sentia naquela época. Todos da família têm a oportunidade de ouvir a sua versão e o que se passou com ele naquele período já que esse assunto nunca fora tratado pela família. Ricardo alega ter sentido muita falta da família. Ele se emociona muito enquanto fala, e sua mãe chora em silêncio enquanto escuta. Ricardo estava trabalhando nessa época, mas abandonou o emprego quando a família convidou-o para passarem as férias juntos. Conta que as coisas estavam difíceis para ele, por isso logo voltou para casa. Na seqüência da Linha da Vida, nota-se também que, quanto às perspectivas dos pais em relação ao futuro, todas se relacionam aos filhos.

Um momento significativo da sessão ocorre quando Sandra conta que a namorada de Ricardo também fuma maconha. Ricardo explode, levanta e anda em direção à porta da sala; quer sair. A terapeuta interfere conseguindo que ele se sente novamente e pede para que algum outro membro da família se ofereça para auxiliar 
numa conversa de Ricardo com a mãe. Carla se oferece. Nessa conversa Ricardo expressa sua mágoa em relação às "fofocas" de Sandra, que denigrem sua imagem. Essa conversa se revela muito significativa para a família, que tem oportunidade de falar, mesmo num estado de muita ansiedade, sobre assuntos ainda não resolvidos. Após o intervalo e a reunião da equipe, a devolução é lida, e a tarefa passada para a família: cada membro deveria escolher uma música que tivesse a ver consigo, mostrar para o resto da família e conversar sobre o assunto.

Em conseqüência da utilização da técnica a questão da droga emergiu. Dessa vez, a terapeuta cria um clima para que o assunto seja enfocado diretamente na sessão. A questão da droga revela diferenças de opiniões entre Paulo e Sandra no que se refere ao exercício da autoridade parental. As diferentes atitudes de cada um em relação ao filho aludem a um conflito entre eles. Percebe-se que Ricardo está triangulado entre pai e mãe, e seu comportamento evita que esse conflito seja abordado diretamente (questão conjugal), passando a ser uma questão parental (Stanton e Todd, 1988). Outra questão que pode ser um indicador de um conflito conjugal é o fato de os eventos citados na Linha da Vida não se referirem ao casal, que se recusa a falar de si próprio nas sessões.

Como visto anteriormente, de acordo com o modelo teórico adotado, o uso de drogas e o comportamento do adolescente podem estar cumprindo uma função estabilizadora no sistema familiar. Ricardo, com suas atitudes, conserva a união da família. O processo de pseudo-individuação pode também ser aqui confirmado. A saída de Ricardo de casa ilustra bem esse processo. Notamos que seu pai demonstrou preocupação com a saída dele e pediu que ele ficasse. Além disso, a saída para perto da avó não significou propriamente a individuação de Ricardo, que se mostrava ainda dependente dos familiares.

No terceiro momento da sessão, a explosão de Ricardo proporcionou à equipe a oportunidade de observar o padrão comunicacional da família e nele intervir. De acordo com a terapia estrutural, as mudanças devem ser iniciadas na própria terapia. Na sessão a família trouxe para a terapia como o conflito ocorre dentro de casa. Entretanto, desta vez, a história teve um desfecho diferente. A seqüência comportamental que se observa normalmente é a de, em uma situação de conflito, algum membro da família se retirar do recinto e deixar o outro falando sozinho. Desta vez a sequiência foi reestruturada: Ricardo foi convidado a permanecer e a conversar com sua mãe sobre o assunto, intermediado por uma irmã.

\section{Quinta sessão}

Participantes: Fernanda, Carla e Ricardo.

Nesta sessão, a ausência dos pais contribui para que a conversa dos filhos gire em torno deles. Os terapeutas perguntam como os filhos vêem a importância dos pais em suas vidas. Eles falam que o pai está mais presente e incentiva mais seus esforços, enquanto a mãe está mais distante, preferindo conversar sobre os filhos com as pessoas de fora da família a falar com eles próprios. A equipe entende isso como a dificuldade do "estar junto", sentida por todos e identificada mais facilmente na atitude da mãe. Os filhos informam que "não dão bola" para Sandra.

Carla aborda a questão conjugal falando que sua mãe sofre há bastante tempo; que seus pais não são um casal. Eles convivem somente. Ricardo acha que falta amor entre eles e diz que o seu pai deve sentir falta, porque "ele é jovem, tá com fogo ainda". Apesar disso, os filhos não conseguem ver os pais separados. "Isso não é impossível, mas não deve acontecer", segundo eles. Só que essa frustração do casal deixa os filhos divididos. Carla diz que sempre defende um dos pais quando o outro vem reclamar ou falar mal. Em resposta a uma pergunta da terapeuta, Carla diz que acha que filho segura 
casamento e que o problema de Ricardo tem aproximado mais os pais, que eles passaram a conversar mais. A terapeuta pergunta se não existe outro meio de os filhos ajudarem os pais sem que estes precisem se sacrificar. Carla diz que depende dos pais e que o papel dos filhos é de cooperar, sendo bons filhos, sem decepcionar os pais. Carla acha que os pais não falariam sobre o seu relacionamento conjugal na sessão e confessa que só está falando porque eles não estão presentes.

Os terapeutas pedem um intervalo para se reunir à equipe e preparam a devolução. Ao final, os terapeutas trazem para os filhos suas dúvidas de como fazer chegar aos pais o conteúdo da sessão. Como transmitir aos pais tal momento? De que maneira torná-los participantes do que acaba de ser falado? Os filhos ficam meio apreensivos, não querendo deixar os pais a par do conteúdo da reunião, mas acabam aceitando a proposta feita pelos terapeutas. A devolução, que será também enviada aos pais em forma de carta, é então lida. Esta gira em torno do cuidado dos filhos com os pais e da questão da "fala" nessa família, que é mais usada por eles "como um chicote, que fere e agride, do que como um afago, que demonstra o amor de um pelo outro".

Os terapeutas agradecem e se despedem, dando por encerrada a sessão. A equipe decide prescrever uma tarefa para o casal: assistir ao filme Shirley Valentine. Quando todos estão se retirando e conversando informalmente, Ricardo comenta, brincando, que sua namorada está viajando e que dará "uns tapas" nela quando retornar. Neste momento, em tom descontraído, Carla diz a Ricardo que ele deveria ser menos agressivo com sua namorada. Inesperadamente, Ricardo explode, mandando Carla não se meter e não tocar no nome de sua namorada. Ambos ficam nervosos, Carla começa a chorar e pede para sair da sala. Tenta-se conversar e mostrar para os dois, enquanto eles discutem alterados, que estão repetindo um acontecimento freqüente em suas casas, e que a terapia é o lugar para se resolver isso de uma maneira diferente da qual eles estão acostumados.

A terapeuta pede a um observador (mestrando) que se encontra na sala de observação para, juntamente com o estagiário, levar Ricardo para uma outra sala enquanto ela permanece com a Carla e a Fernanda. Na sala onde se encontram as mulheres, Carla diz que sempre é assim, que o Ricardo vai mudar e que ela não virá mais às sessões. A terapeuta procura mostrar a ela a importância de seu papel nas sessões e pede que veja o que aconteceu de uma outra forma.

Enquanto isso, o estagiário e o observador conversam com Ricardo, que se acalma um pouco mais. Os terapeutas procuram esclarecer que o que aconteceu foi mais uma "erupção vulcânica", tão comum na forma de comunicação da família.

Muito pôde ser observado nessa sessão. A ausência dos pais permitiu que a questão conjugal fosse tratada pela primeira vez no processo terapêutico. Pelo discurso dos filhos, percebe-se que eles têm consciência de que a relação conjugal de seus pais não vai bem. Além disso, nota-se que os filhos, muitas vezes, se encontram no meio de um conflito conjugal, já que os pais não conseguem resolver suas diferenças diretamente um com o outro. Isso mostra que a questão da triangulação vivida pela família não é algo exclusivo da relação do paciente identificado com os pais. Uma observação interessante de Carla é a de que "filho segura casamento" e "o problema do Ricardo fez com que eles [os pais] conversassem mais". Essa pequena análise da situação dos filhos na família nos remete a Stanton e Todd (1988), principalmente quando pensamos na função que o comportamento de Ricardo - inclusive seu envolvimento com drogas - está cumprindo no sistema familiar: desviar o foco da questão conjugal para a questão parental.

Outro ponto percebido na sessão é o paradoxo que a família vive: eles cuidam um do outro se afastando. Segundo a equipe, eles ainda não sabem andar juntos e, para 
que isso ocorra, a família tem de pensar melhor sobre a função da palavra e como ela pode ser usada. "A fala nessa família costuma estourar como uma bomba. Ela ainda só é usada para agredir. É preciso trabalhar para que a palavra passe a ser usada como carícia e não mais como um chicote." Assim, a contradição "intimidade $x$ agressividade" pode ser resolvida sem precisar que um extremo leve, obrigatoriamente, a outro. Desse modo, a família pode se aprofundar mais em todos os níveis de relacionamento.

Atenção especial deve ser dada também ao ocorrido no final da sessão. $\mathrm{O}$ conflito ilustra bem a violência nos padrões comunicacional e relacional mantido pela família, ou seja, quando a intimidade de alguém é invadida, ocorre uma explosão de agressividade, seguida por um ímpeto de afastamento por parte dos envolvidos no conflito. Essa seqüência comportamental segue o padrão da analisada na terceira sessão. É interessante notar que o evento que antecede o comportamento de explosão é semelhante nos dois casos: um comentário que envolve a namorada de Ricardo.

Em contrapartida, com essa manifestação de violência, pode-se fazer também um paralelo ilustrativo da função do adolescente usuário de drogas em sistemas familiares em crise. Stanton e Todd (1988) dizem que o drogadito junto aos pais forma um único sistema e que, quando o subsistema conjugal é ameaçado, "o adito se ativa, sua conduta muda criando uma situação que dramaticamente concentra a atenção sobre ele [...] podendo ser um ataque de fúria" (Stanton e Todd, 1988, p. 122).

Durante a sessão, falou-se muito na relação conjugal, que os pais não vivem como um casal etc. Procurou-se, ao final, encontrar uma forma de os filhos participarem aos pais tudo o que foi comentado na sessão, o que gerou grande ansiedade. Pode-se interpretar o ataque de fúria de Ricardo como uma tentativa de trazer para si todas as atenções, desviando o foco dos conflitos conjugais.

\section{COMENTÁRIOS FINAIS}

O caso apresentado constitui um exemplo bastante representativo de um modelo de atendimento, realizado pelos autores, a adolescentes drogaditos na perspectiva familiar.

No que se refere à relação conjugal, é importante ressaltar que a hipótese do conflito é comumente utilizada por terapeutas familiares. Ausloos (1996) alerta para o perigo de considerar o conflito conjugal como uma hipótese de disfunção familiar, colocando o casal como a causa do problema. Na dinâmica dessa família, no entanto, a questão conjugal tem sua importância confirmada no decorrer dos atendimentos. Não se trata de atribuir ao casal a culpa pelo problema da drogadição de Ricardo, mas de levar em conta toda a complexidade da dinâmica familiar, incluindo-se nesta a dinâmica do casal. Como tratado na análise da quinta sessão, existem triangulações significativas na família, e elas evitam que o conflito conjugal existente emerja para o primeiro plano. Os filhos estão constantemente no terceiro vértice desses triângulos, sendo que Ricardo é o ocupante mais freqüente.

A partir da quinta sessão, em que só os filhos estiveram presentes, a relação do casal é tratada de forma mais direta na sessão. Na sexta sessão (não descrita no presente texto), o casal pôde falar de sua relação enquanto seus filhos escutavam: "Com o passar do tempo, meu casamento foi esfriando". Suas diferenças são explicitadas e o descontentamento de ambos em relação a esse fato fica claro. Percebe-se a importância desse momento no processo terapêutico através do comportamento dos filhos, que escutam com atenção, em silêncio absoluto. Com o auxílio dos terapeutas, as diferenças entre o casal não são tratadas, nesse momento, de forma triangulada, o que representa um exemplo do que o modelo de intervenção propõe: intervenções estruturais 
focalizando mudanças de seqüências comportamentais na própria sessão (Stanton e Todd, 1988).

O processo de pseudo-individuação (Stanton et al., 1988) evidencia-se claramente no caso apresentado. Por um lado, Ricardo sofre pressões para individuar-se. Sua família e a comunidade esperam que ele conquiste autonomia, ingresse em uma faculdade, consiga um emprego. Por outro lado, percebemos que a permanência de Ricardo como o membro problemático, como o filho que não cresce, cumpre uma função estabilizadora na dinâmica familiar. Dessa forma, o uso de drogas se apresenta como uma solução paradoxal desse dilema: Ricardo consegue separar-se da família, namora, sai com os amigos. Entretanto, essa saída ocorre de forma que seus pais permaneçam preocupados com ele, o que o mantém triangulado entre os dois. Essa é a funcionalidade do processo de pseudo-individuação, que preserva a homeostase familiar, permanecendo o conflito conjugal na penumbra.

A rotulação cumpre um papel fundamental nessa dinâmica. A partir do momento que um membro da família é definido como o problema, todos os outros se isentam de sua participação nas questões familiares. Percebemos que nesse processo terapêutico Ricardo foi sendo gradativamente tirado da posição de bode expiatório. Na sétima sessão (não descrita no presente texto), o pai afirma que a família admite não serem Ricardo e a droga as principais questões a serem resolvidas na família. Todos estão implicados na situação; desse modo, a participação de todos se faz necessária para que a mudança possa ocorrer. Nessa sessão, o adolescente esboçou alguma melhora em seu comportamento à medida que deixou de ser visto como "o filho pródigo". Isso se apresenta como uma questão fundamental indicada pelo presente estudo e aponta para a necessidade de se dedicar atenção especial aos processos de rotulação e designação precoce presentes em famílias de adolescentes em situação de uso de drogas.

O comportamento agressivo de Ricardo revela mais uma faceta da dinâmica familiar: a violência. Explosões de violência ocorreram dentro das próprias sessões, quando fronteiras foram atravessadas, denunciando o padrão comunicacional da família. O isolamento entre os membros da família constitui, portanto, uma forma de evitação dos conflitos familiares. Por meio de seqüências comunicacionais como as apresentadas na terceira e quinta sessões, a violência se perpetua na família. É interessante notar que esse padrão comunicacional da família acaba por preservar a sua união. "Explosões de raiva" e "abandono do campo de batalha" impedem que a família chegue a uma escalada simétrica (Watzlawick et al., 1967, p. 96) e, portanto, preservam a sua união. Além disso, com receio de que esses episódios violentos ocorram novamente, os membros da família mantêm uma distância segura e, assim, seguem se relacionando.

O manejo dos conflitos que se sucederam nas sessões é um exemplo de intervenções estruturais-estratégicas do modelo de atendimento. Nas sessões, alianças, provocações, redefinições e outros recursos foram utilizados com o objetivo de manejar a crise no sistema familiar. O lidar com essa crise no setting terapêutico foi o que permitiu que as seqüências comunicacionais pudessem ser modificadas, para poderem sofrer transformações também fora do contexto terapêutico.

Nos atendimentos subseqüentes, somente o pai esteve presente, funcionando como porta-voz da família no que se refere à interrupção do tratamento. A equipe compreende esse movimento de afastamento da terapia de uma forma sistêmica e esclarece isso para a família, ampliando seu campo de visão. As duas últimas sessões desse processo tiveram como característica o impasse da família em continuar com o processo terapêutico. Os significados da desistência ou continuidade do tratamento foram explorados na análise da sétima sessão (não descrita no presente texto). De fato, continuar implicaria um trabalho tortuoso e pouco confortável, já que as mudanças 
apenas iniciadas demandariam todo um reajustamento do sistema familiar, que teria de aprender a conviver com base em novas regras, novos padrões, novas relações entre seus membros. Essa transformação ameaçaria a estabilidade familiar e traria ansiedade, sobretudo no que se refere à situação do casal.

As duas últimas sessões mostraram que mudanças de fato ocorreram na vida da família. O alcance dessas mudanças é que se revela algo impossível de ser previsto. Talvez o processo iniciado tenha sido o suficiente para que a família retomasse seu desenvolvimento; talvez as mudanças só tenham real efeito após algum tempo... O fim da terapia não significou, certamente, o fim da história dessa família.

\begin{abstract}
The present study aims the presentation of a family therapy model witch takes place in the clinic of an university. The presentation is based on the exposition of theoretical references and on a clinical case study. Tree family therapy sessions are described here. The context is of drug addiction in a family with father, mother and tree adolescents. The analysis instrument are registration forms and video recordings of the sessions. The analysis is based on a clinical case study method and points to four main aspects: stigmatization, couple relation, pseudoindividuation and violence.
\end{abstract}

Keywords: family therapy, adolescence, drug addiction.

Notas

${ }^{1}$ Informações alteradas para não permitir a identificação dos participantes.

${ }^{2}$ Organização não-governamental que apresenta uma abordagem de mudança comportamental destinada a pais, professores, pedagogos e terapeutas, passível de ser utilizada para problemas como a dependência química (Menezes, 2000). 


\section{Referências}

ANDOLFI, M. A. Terapia familiar. Lisboa: Vega, 1981.

AUSLOOS, G. A competência das famílias: tempo, caos, processo. Lisboa: Climepsi Editores, 1996.

BOSCOLO, L. et al. A terapia familiar sistêmica de Milão. Conversações sobre teoria e prática. Porto Alegre: Artes Médicas, 1993.

BUCHER, R. Drogas e drogadição no Brasil. Porto Alegre: Artes Médicas, 1992.

CALANCA, A. A. Toxicomania entre doença e delinqüência. In: BERGERET, J.; LEBLANC, J. Toxicomanias: uma visão multidisciplinar. Porto Alegre: Artes Médicas, 1991.

COSTA, L. F.; SUBDRACK, M. F. O. Terapia familiar com famílias recasadas num contexto de usuários de drogas. Trabalho apresentado no X Congresso Brasileiro de Psicodrama, Rio Quente, Goiás, 1996.

GONZÁLEZ-REY, F. Epistemologia cualitativa y subjetividad. Ciudad de La Habana: Editorial Pueblo y Educación, 1997.

HALEY, J. Trastornos de la emancipación juvenil y terapia familiar. Buenos Aires: Amorrortu, 1985.

MENEZES, M. S. C. O que é amor exigente. 22. ed. São Paulo: Loyola, 2000.

MINUCHIN, S. Famílias: funcionamento e tratamento. Porto Alegre: Artes Médicas, 1982.

SELEKMAN, M. D. La evolución de un modelo de terapia breve para adolescentes con problemas. In: SELEKMAN, M. D. (Org.). Abrir caminos para el cambio: soluciones de terapia breve para adolescentes con problemas. Barcelona: Gedisa, 1996. p. 13-34.

SELVINI PALAZZOLI, M. et al. Paradoja y Contraparadoja. Un nuevo modelo en la terapia de la familia de transacción esquizofrenica. Buenos Aires: Paidós, 1988.

STANTON, M. D.; LANDAU-STANTON, J. Terapia con familias de adolescentes drogadictos. Sistemas familiares, 1991.

STANTON, M. D.; TODD, T. C. El modelo terapeutico. In: STANTON, M. D.: TODD, T. C. (Org.). Terapia familiar del abuso y adicción a las drogas. Buenos Aires: Editorial Gedisa, 1988. p. 101-133.

STANTON, M. D. et al. Un modelo conceptual. In: STANTON, M. D.; TODD, T. C. (Org.). Terapia familiar del abuso y adicción a las drogas. Buenos Aires: Editorial Gedisa, 1988. p. 25-42.

STERNSCHUS, S.; ANGEL, P. O toxicômano e sua família. In: BERGERET, J.; LEBLANC, J. Toxicomanias: uma visão multidisciplinar. Porto Alegre: Artes Médicas, 1991.

SUDBRACK, M. F. O. Da falta do pai à busca da lei: o significado da passagem ao ato delinqüente no contexto familiar e institucional. Psicologia: Teoria e Pesquisa, v. 8, p. 447-457, 1992.

WATZLAWICK, P.; BEAVIN, J. H.; JACKSON, D. D. Pragmática da comunicação humana. São Paulo: Cultrix, 1967. 